\title{
Capillaroscopic findings in children and adolescents with raynaud's phenomenon: results from study in 92 patients
}

\author{
Berta Lopez Montesinos, Maria Isabel Gonzalez Fernandez,' Laura Fernandez Silveira, Inmaculada Calvo Penades \\ From 21st European Pediatric Rheumatology (PReS) Congress \\ Belgrade, Serbia. 17-21 September 2014
}

\section{Introduction}

Raynaud's phenomenon (RP) appears to be underestimated in the pediatric population and its prevalence is unknown. However, RP is the earliest and the most common clinical manifestation of diffuse connective tissue diseases.

Nailfold capillaroscopy is an easily performed, nontraumatic and low cost technique, with a confirmed role in discrimination between primary and secondary RP, playing an important role in the assessment of autoimmune rheumatic diseases.

\section{Objectives}

Identify all patients registered as RP in a Pediatric Rheumatology Unit. Describe the demographic and clinical features of these patients. Assess nailfold capillaroscopy in these children and adolescents with RP and the relation of the clinical features to the capillaroscopic pattern.

\section{Methods}

Medical records (2003-2013) from patients with RP followed in our Pediatric Rheumatology Unit were reviewed for demographic data, familial history, trigger factors, Raynaud pattern, clinical manifestations, associated conditions and auto-antibodies positivity. Capillaroscopic patterns were defined as normal (NP), nonspecific pathological (NPP) and specific pathological (SPP). Capillaroscopy was performed, distinguishing primary RP (PRP), secondary RP (SRP) and undifferentiated RP (URP). Associated autoimmune rheumatic diseases: systemic sclerosis (SSc), juvenile dermatomyositis (JDM),

Pediatric Rheumatology Unit, Hospital La Fe, Valencia, Spain systemic lupus erythematosus (SLE), mixed connective tissue disease (MCTD).

\section{Results}

101 patients with RP, F:M 84:16. Age at onset 10,42 +/3,70 years old. RP classification: $28 \%$ PRP, $35 \%$ SRP, $37 \%$ URP. Familial history: 20\% rheumatic disease, 7\% RP. Trigger factor: $73 \%$ cold, $8 \%$ stress, $8 \%$ exercise. Raynaud pattern: $31 \%$ single-phase, $53 \%$ two-phase, $16 \%$ threephase. Clinical manifestations: livedo reticularis $66 \%$, arthritis $34 \%$ and digital ulcers 16\% in SRP; arthralgia 40\%, perniosis $28 \%$. Associated conditions: 7 MCTD, 8 JDM, 10 SLE, 3 SSc, 2 localized scleroderma, 1 CREST syndrome, 2antiphospholipid syndrome (APS), 3 juvenile idiopathic arthritis, 1 Behçet's disease. Auto-antibodies: ANA $+48 \%$, ENA $+10 \%$, DNA $+7 \%$. Capillaroscopy was performed in 92 patients, with mean follow-up time of 5,45 years. Out of 92 patients, 56 (61\%) had NP, 14 (15\%) NPP, 22 (24\%) SPP. NP: 38 PRP, 9 SRP, 10 URP. NPP: 5 SRP, 9 URP. SPP: 20 SRP, 2 URP. Autoimmune rheumatic diseases with capillaroscopic pattern: SSc (1NP, 2 SPP), JDM (2 NPP, 6 SPP), SLE (4 NP, 2 NPP, 4 SPP), MCTD (1 NPP, 6 SPP), CREST (1SPP), APS (1 NP, 1 SPP). During the follow-up, 7 patients with NP changed to SPP (3 MCTD, 2 SLE, 1 CREST and 1 SSc). 54\% were treated with transdermal nitroglycerine, $30 \%$ with nifedipine and $5 \%$ with bosentan.

\section{Conclusion}

In our series we found a marked female predominance of RP, with a mean age of onset 10 years old. Compared with RP in the adulthood, we found a more frequent single- or two-phase pattern, and a higher association with systemic connective tissue diseases. These results are similar to those reported in other series. 


\section{Disclosure of interest}

None declared

Published: 17 September 2014

doi:10.1186/1546-0096-12-S1-P283

Cite this article as: Montesinos et al:: Capillaroscopic findings in children and adolescents with raynaud's phenomenon: results from study in 92 patients. Pediatric Rheumatology 2014 12(Suppl 1):P283.

Submit your next manuscript to BioMed Central and take full advantage of:

- Convenient online submission

- Thorough peer review

- No space constraints or color figure charges

- Immediate publication on acceptance

- Inclusion in PubMed, CAS, Scopus and Google Scholar

- Research which is freely available for redistribution

Submit your manuscript at www.biomedcentral.com/submit
Ciomed Central 